\title{
ATTITUDE TOWARDS MENTAL ILLNESS AMONG STAFF NURSES IN A TERTIARY CARE HOSPITAL- A HOSPITAL-BASED CROSS-SECTIONAL STUDY
}

\author{
Kavitha Mukesh', Arun Madhumal Palayat², Kalathara Francis Yesudas ${ }^{3}$, Binoo Divakaran ${ }^{4}$ \\ ${ }^{1}$ Junior Resident, Department of Psychiatry, Academy of Medical Sciences, Pariyaram, Kannur. \\ ${ }^{2}$ Associate Professor, Department of Psychiatry, Academy of Medical Sciences, Pariyaram, Kannur. \\ ${ }^{3}$ Professor and HOD, Department of Psychiatry, Academy of Medical Sciences, Pariyaram, Kannur. \\ ${ }_{4}^{4}$ Associate Professor, Department of Biostatistics, Academy of Medical Sciences, Pariyaram, Kannur.
}

\begin{abstract}
\section{BACKGROUND}

Worldwide despite growing evidence of the importance of mental health for economic, social and human capital, people with mental health problems and even the very concept of mental health, receive negative publicity and are stigmatised in public perceptions. Negative and stigmatising attitudes are found even among healthcare staff including nurses. Today, the focus of psychiatric care is on de-institutionalisation: this depends on a number of key conditions, of which tolerance and nondiscrimination are among the most important. To deal with that problem, intervention has to be started from the healthcare professional's level itself, for which the present attitude of them has to be understood.
\end{abstract}

The aim of this study is to assess the attitude of nurses towards patients with mental illness in a tertiary care hospital.

\section{MATERIALS AND METHODS}

Staff nurses in each ward are approached, were given socio-demographic data sheet and attitude towards Mental Illness questionnaire.

\section{RESULTS}

We approached 140 staff nurses working in various wards, ICU's and casualty of Pariyaram Medical College; 27 were not willing to participate in the study. Among the 113 participated, 10 had to be excluded due to incomplete data sheet. Final sample size of the study was 103 . Most of them (90\%) were females, in younger age group; $75 \%$ were married and $73 \%$ were from nuclear families. Majority (83\%) had diploma in nursing; 74\% of them were having > 10 years of experience as staff nurse. Only 35\% of them had experience in psychiatry ward; $25 \%$ of them had got training in psychiatry. Positive and negative attitudes were analysed in each subscales showing more of positive attitude in all subscales except for pessimistic prediction. Younger age group nurses (20 - 30) showed more positive attitude towards mental illness when compared to older age group (31 - 50). Males showed more positive attitude in all subscales except for benevolence. Female nursing staffs showed more benevolence scores. Nurses who were married had more positive attitude. Nurses with diploma had more positive attitude than nurses with BSc degree. Training in psychiatry during their nursing course was not found to changing the attitude. Experience in psychiatry ward showing significant negative attitude in stereotypy.

\section{CONCLUSION}

This study explored the attitude of nurses towards mental illness in tertiary level general hospital settings. This is pointing out the area to be intervened to abate discrimination and stigma regarding mental illness in the society.

\section{KEYWORDS}

Attitude, Mental Illness, Staff Nurses, Stigma.

HOW TO CITE THIS ARTICLE: Mukesh K, Palayat AM, Yesudas KF, et al. Attitude towards mental illness among staff nurses in a tertiary care hospital- a hospital-based cross-sectional study. J. Evolution Med. Dent. Sci. 2017;6(27):2231-2235, DOI: $10.14260 /$ Jemds/2017/481

\section{BACKGROUND}

Mental health has got increasing importance for economic, social and human capital worldwide. In spite of this fact, mental health issues continue to have negative and stigmatising social perception. Not only the mentally ill people but also their family, the mental health services and professionals and even the very concept of mental health is

Financial or Other, Competing Interest: None.

Submission 25-02-2017, Peer Review 20-03-2017,

Acceptance 27-03-2017, Published 03-04-2017.

Corresponding Author:

Dr. Kavitha Mukesh,

Vasantham, Kunnakkavu P. O.,

Cherukara, Malappuram-679340,

Kerala.

E-mail: drkavithamukesh01@gmail.com

DOI: $10.14260 /$ jemds $/ 2017 / 481$ receiving negative publicity.[1,2] The prevalence of mental disorders in India is high as in other parts of the world. ${ }^{[3]}$ It is estimated that at least 58/1000 Indians have a mental illness[ ${ }^{[4]} ; 10$ million suffer from severe mental illnesses.[5]

Today, the focus of psychiatric care is on deinstitutionalisation: this depends on a number of key conditions, of which tolerance and non-discrimination are among the most important.[6] In India, 90\% of people with psychiatric illnesses live with their families. Their long-term care within the family and community depends on the opinion and attitude of the people around about mental illness. Further, a positive attitude towards mental illness is a prerequisite for the provision of holistic care.[7]

However, persistent negative attitudes and the social rejection of people with mental illness have prevailed throughout history. Negative attitudes like stigmatisation, discrimination, neglect, avoidance and violence towards the 
mentally ill are widespread among the general public. Lack of awareness about mental illness is the main culprit for this. Studies show that members of the public who have more knowledge about mental illness are less likely to endorse stigmatising attitudes.[8]

Literature shows that some non-psychiatric health professionals even including postgraduates often show negative attitudes and poor knowledge about mental illness.[9] Psychiatric exposure of medical and paramedical staff during training is grossly inadequate and eventually leads to insufficient knowledge and misconceptions about psychiatric illnesses and their treatment.[9,10,11] Negative and stigmatising attitudes also are found among healthcare staff including nurses. This to a surprising extent are in several respects comparable with public opinion.[12] Lack of knowledge, lower education level, less professional experience and lack of familiarity contribute to it.

Here, in this study, we are trying to understand about the nursing staffs' attitude towards mental illness, how it is varied among nurses based on their various sociodemographic factors.

\section{Need for the Study}

Staff nurses spend more time with patients in the inpatient care. Responsible and professional approaches of nursing staff are essential for adequate patient care. Lack of knowledge, skills and poor attitude of these professionals may lead to inadequacies in treatment provided.

Nurses with proper knowledge and appropriate attitude towards mental illness can identify and refer patients in need of psychiatric care to a mental health professional.

Nurses can educate families of mentally ill about mental illness, thereby removing stigma of treatment. Positive attitude towards mentally ill can help them build a rapport with the patient, which may help in improving treatment adherence.

Nurses can spend more time with the patient. This may help them to educate and clarify doubts of patients regarding illness and treatment provided. Good attitude of the nurses can bridge the gap between the patient and the doctor, thereby improving treatment adherence and well-being of the patient.

This study would help to know the general attitude of nurses to the mentally ill, which may be used to improve the quality of mental health services.

\section{Aim}

The aim of the study was to understand the attitude of staff nurse towards the mental illness. All those who were working as staff nurse in Pariyaram Medical College during 2015 September to October were included. Those who were not ready to participate were excluded.

\section{MATERIALS AND METHODS}

This was a hospital-based cross-sectional study. All staff nurses, both males and females, irrespective of their degree (GNM, BSc, Post nursing diploma, MSc) working in various wards including ICU and Casualty constituted the study population. Consecutive staff nurses who were willing to participate were included and were provided with sociodemographic data sheet and ASMI questionnaire. They were instructed to respond to it independently, taking a maximum of 20 minutes and return it. These sheets were collected and analysed.

Pariyaram Medical College has got around 200 permanent staff nurses excluding those who are working on temporary basis and those who are exclusively posted in super speciality wards. We could approach 140 of them as a part of our study. The rest (Around 60) were not available during the study period due to their shift system changes and long leaves.

\section{Materials}

1. Socio-demographic data sheet.

2. The Attitude Scale for Mental Illness (ASMI).

The Attitude Scale for Mental Illness (ASMI) is a valid and reliable self-report that measures respondents' attitude to mental illness. It uses 34 items divided into six broad conceptual subscales.

- Benevolence or paternalistic and sympathetic views.

- Separatism or attitude to discrimination.

- Stereotyping or the degree of social distance maintained from the mentally ill.

- Restrictiveness or perception of the mentally ill as a threat to society.

- Pessimistic prediction or level of prejudice towards mental illness.

- Stigmatisation or discriminatory behaviour towards those with mental illness.

Respondents are given the choice of 5 Likert scale responses (totally disagree $=1$, almost totally disagree $=2$, sometimes agree $=3$, almost totally agree $=4$, totally agree $=$ 5) based on their feelings towards each of the 34 items.

Minimum and maximum scores in each subscale were taken to calculate the cut-off score. In all except Benevolence subscale, the score coming below the cut-off value were taken as positive attitude and above the cut-off value were taken as negative attitude. In benevolence, it is vice versa.

$\begin{array}{lll}\text { Separatism } & - & 11-32 \text { (Cut-off score = 33) } \\ \text { Stereotyping } & - & 4-11(12) \\ \text { Restrictiveness } & - & 4-11(12) \\ \text { Benevolence } & - & 22-35(22) \\ \text { Pessimistic prediction } & - & 4-11(12) \\ \text { Stigmatisation } & - & 4-11(12)\end{array}$

\section{Analysis}

The data were analysed using statistical software and results were presented in narratives and tables. Descriptive (Frequency and percentage) and inferential statistics (Chisquare test) were used to interpret the data. Statistical significance was assumed at $\mathrm{p}<0.05$.

\section{Ethical Consideration}

Ethical clearance was obtained from Institutional Ethical Committee.

\section{RESULTS}

We approached 140 staff nurses working in various wards, ICU's and casualty of Pariyaram Medical College; 27 were not willing to participate in the study. Among the 113 participated, 10 had to be excluded due to incomplete data sheet. Final sample size of the study was 103. 


\begin{tabular}{|c|c|c|}
\hline Category & Sub-Class & Percentage \\
\hline Sex & Male & $10 \%$ \\
\hline Age & Female & $90 \%$ \\
\hline & $20-30$ & $60 \%$ \\
\hline Religion & $31-50$ & $40 \%$ \\
\hline & Hindu & $56 \%$ \\
\hline Marital Status & Christian & $44 \%$ \\
\hline & Married & $75 \%$ \\
\hline Family Type & Unmarried & $25 \%$ \\
\hline & Nuclear & $73 \%$ \\
\hline Level of Education & Joint & $27 \%$ \\
\hline & Degree & $17 \%$ \\
\hline Years of Experience & Diploma & $83 \%$ \\
\hline & $<10$ Years & $26 \%$ \\
\hline
\end{tabular}

Most of them (90\%) were females, in younger age group. $75 \%$ were married and $73 \%$ were from nuclear families. Majority (83\%) had diploma in nursing; $74 \%$ of them were having $>10$ years of experience as staff nurse. Only 35\% of them had experience in psychiatry ward; $25 \%$ of them had got training in psychiatry.

\begin{tabular}{|c|c|c|}
\hline & Yes (\%) & No (\%) \\
\hline Experience in Psychiatry & 35 & 65 \\
\hline Training in Psychiatry & 25 & 75 \\
\hline Family history of Psychiatric illness & 10 & 90 \\
\hline Past history of Psychiatric illness & 6 & 94 \\
\hline
\end{tabular}

\begin{tabular}{|c|c|c|}
\hline Sub-Class & $\begin{array}{c}\text { Positive } \\
\text { (\% of Nurses) }\end{array}$ & $\begin{array}{c}\text { Negative } \\
\text { (\% of Nurses) }\end{array}$ \\
\hline Separatism & 83.5 & 16.5 \\
\hline Stereotyping & 57.3 & 42.7 \\
\hline Restrictiveness & 79.6 & 20.4 \\
\hline Benevolence & 86.4 & 13.6 \\
\hline Pessimistic Prediction & 39.8 & 60.2 \\
\hline Stigmatisation & 68.9 & 31.1 \\
\hline \multicolumn{3}{|c|}{ Positive and Negative Attitude in Each Sub-Class } \\
\hline
\end{tabular}

Positive and negative attitudes were analysed in each subscales, showing more of positive attitude in all subscales except for pessimistic prediction.

\begin{tabular}{|c|c|c|c|c|c|c|c|}
\hline \multicolumn{2}{|c|}{ Socio-Demographic Factors } & \multirow{2}{*}{$\begin{array}{c}\text { Separatism } \\
85.5\end{array}$} & \multirow{2}{*}{$\begin{array}{c}\text { Stereotyping } \\
58.1\end{array}$} & \multirow{2}{*}{$\begin{array}{c}\text { Restrictiveness } \\
80.6\end{array}$} & \multirow{2}{*}{$\begin{array}{c}\text { Benevolence } \\
90.3\end{array}$} & \multirow{2}{*}{$\begin{array}{c}\begin{array}{c}\text { Pessimistic } \\
\text { Prediction }\end{array} \\
37.1\end{array}$} & \multirow{2}{*}{$\begin{array}{c}\text { Stigmatisation } \\
64.5\end{array}$} \\
\hline A & $20-30$ & & & & & & \\
\hline Age & $31-50$ & 80.5 & 56.1 & 78 & 80.5 & 43.9 & 75.6 \\
\hline \multirow{2}{*}{ Sex } & Male & 90 & 70 & 90 & 80 & 40 & 80 \\
\hline & Female & 82.8 & 55.9 & 78.5 & 87.1 & 39.8 & 68.9 \\
\hline \multirow{2}{*}{$\begin{array}{l}\text { Marital } \\
\text { Status }\end{array}$} & Married & 81.8 & 58.4 & 80.5 & 88.3 & 40.3 & 71.4 \\
\hline & Single & 87.5 & 50 & 75 & 79.2 & 33.2 & 62.5 \\
\hline \multirow{3}{*}{$\begin{array}{l}\text { Family } \\
\text { Type }\end{array}$} & Nuclear & 84 & 57.3 & 78.7 & 85.3 & 38.7 & 74.7 \\
\hline & \multirow[t]{2}{*}{ Joint } & \multirow[t]{2}{*}{82} & \multirow[t]{2}{*}{57.1} & \multirow{2}{*}{82.1} & \multirow{2}{*}{89.3} & \multirow{2}{*}{42.9} & 53.6 \\
\hline & & & & & & & ${ }^{*} \mathrm{P}=0.036$ \\
\hline \multirow[b]{2}{*}{ Education } & Degree & 82.4 & 29.4 & 76.5 & 82.4 & 41.2 & 64.7 \\
\hline & Diploma & 83.7 & $\begin{array}{c}62.8 \\
* \mathrm{P}=0.016\end{array}$ & 80.2 & 87.2 & 39.5 & 69.8 \\
\hline \multirow{2}{*}{ Years of Experience } & $<10$ years & 85.5 & 55.3 & 78.9 & 88.2 & 39.5 & 67.1 \\
\hline & $>10$ years & 77.8 & 63 & 81.5 & 81.5 & 40.7 & 74.1 \\
\hline \multirow[b]{2}{*}{$\begin{array}{c}\text { Experience in } \\
\text { Psychiatry Ward }\end{array}$} & Yes & 89.2 & 43.2 & 78.4 & 91.9 & 48.6 & 73 \\
\hline & No & 80.3 & $\begin{array}{c}65.2 \\
\mathrm{P}=0.026\end{array}$ & 80.3 & 83.3 & 34.8 & 66.7 \\
\hline \multirow{2}{*}{$\begin{array}{l}\text { Training in } \\
\text { Psychiatry }\end{array}$} & Yes & 84.6 & 53.8 & 76.9 & 92.3 & 46.2 & 69.2 \\
\hline & No & 83.1 & 58.4 & 80.5 & 84.4 & 37.7 & 68.9 \\
\hline \multirow{2}{*}{$\begin{array}{c}\text { Family history } \\
\text { of Psychiatric Illness }\end{array}$} & Positive & 63.6 & 63.6 & 72.7 & 90.9 & 36.4 & 74.7 \\
\hline & Negative & 85.9 & 56.5 & 80.4 & 85.9 & 40.2 & 53.6 \\
\hline \multirow{2}{*}{$\begin{array}{c}\text { Past history } \\
\text { of Psychiatric Illness }\end{array}$} & Yes & 42.9 & 57.1 & 85.7 & 71.4 & 71.4 & 100 \\
\hline & No & 86.5 & 57.3 & 79.2 & 87.5 & 37.5 & 66.7 \\
\hline
\end{tabular}

Generally, the study group has more positive attitude. Younger age group nurses (20 - 30) showed more positive attitude towards mental illness when compared to older age group (31 - 50). Males showed more positive attitude in all subscales, except for benevolence. Female nursing staffs show more benevolence scores in ASMI than males. Nurses who were married had more positive attitude. Nurses with diploma had more positive attitude than nurses with BSc degree. Training in psychiatry during their nursing course was not found to changing the attitude. Experience in psychiatry ward showing significant negative attitude in stereotypy.

\section{DISCUSSION}

Attitude of nurses towards mental illness in the study hospital is generally more positive. Staff nurses had positive attitude in separatism, stereotyping, restrictiveness, benevolence and stigmatisation subscales with a maximum positive score shown in benevolence. Still, pessimistic prediction subscale showed more negative attitude.

Younger age group nurses (20 - 30) showed more positive attitude towards mental illness when compared to older age group (31 - 50). As per NHS survey report 2011, in the general population the oldest group (Age 55+) had the most negative attitudes towards people with mental illness. The young people were less likely to hold negative attitudes around fear and exclusion than those aged 55+. Levels of 
understanding and tolerance of mental illness were higher in older people.[13]

Males showed more positive attitude in all subscales except for benevolence. Female nursing staffs show more benevolence scores in ASMI than males. Previous studies also demonstrated more tolerant attitudes in females.[13]

Nurses who were married had more positive attitude when compared with their unmarried/separated colleagues. Nurses from nuclear family showed more positive attitude in stigmatisation subscale when compared with those from joint family, which is statistically significant with a $p$ value of 0.036 .

In a study by Arvaniti A et al in health service staff, a comparatively large number of sample held negative attitudes, especially concerning social discrimination and restriction of the patients. Women, older and less educated staff, nursing staff and people scoring higher on authoritarianism were more prejudiced.[14]

$6.8 \%$ of total studied population had past history of psychiatric illness. They showed significantly more negative attitude in separatism with $100 \%$ positive attitude in stigmatisation. Family history of psychiatric illness did not cause any change in their attitude.

Nurses with diploma had more positive attitude than nurses with BSc degree, noted especially in stereotyping questions with a statistically significant $p$ value of 0.016 . Nurses with prior experience in psychiatry ward showed more positive attitude generally, but significant negative attitude was observed in stereotyping subscale with a $p$ value of 0.026 . Previous studies also showed that higher scores on familiarity were associated with less negative attitudes.[14] The reason for more stereotyping negative attitudes with experience in our sample could be due to the fact that most of the time the nurses here are getting posting in psychiatry ward as a punishment, which itself could have contributed to this negative attitude.

When compared to general population, medical and other paramedical professionals are expected to be having more scientific approach and attitude to illnesses, which they are acquiring through their education. In contrary to our expectations, training in psychiatry during their nursing course was not found to be resulting in positive attitude towards mental illness. Here, we need to search for the problem with the training programme. There are a lot of similar results obtained in previous studies conducted in healthcare professionals or students.

Hugo $M$, in their study on various mental health professionals came to a conclusion that professional groups were found to be less optimistic about prognosis and less positive about likely long-term outcomes when compared with the general public. Medical staffs were less optimistic about outcomes than other professional groups with mental health nurses, generally most optimistic.[15]

Frances Brinn in their study found that nurses were wary of the possible unpredictable behaviour of people with mental health problems. But qualified and experienced staffs were generally better equipped to cope up with it.[16]

There are studies on medical and other paramedical undergraduate students' attitude towards mental illness. Vijayalakshmi Poreddi in their study found that the nursing students have significant positive attitudes towards mental illness in three of the six attitudes factors- restrictiveness, benevolence and stigmatisation. But they have negative attitudes in separatism, stereotype and pessimistic predictions domains.[17]

The undergraduate medical student population had significant shortcomings in knowledge and attitude pertaining to psychiatric disorders, more glaring in the initial years of education.[18] Sireesha SR et al in their study highlighted that exposure to psychiatry posting partially improving the attitude of medical students towards mental illness.[19]

\section{CONCLUSION}

This study explored the attitude of nurses towards mental illness in tertiary level general hospital settings. This points out the area to be intervened to abate discrimination and stigma regarding mental illness in the health professionals. The better knowledge about the mental illness will ensure better understanding and more empathetic approach to the patient from the nurses. For this, proper training programme in psychiatric care should be included in their curriculum. There should be a good advisory board and special checking systems for eliminating the lacunae in the mental healthcare training and practices.

\section{Limitations}

- Small sample size.

- Study conducted at a single tertiary hospital.

- No comparative group.

\section{Future Directions}

- To compare the attitudes of other medical staff towards mental illnesses in a similar setup.

- To conduct studies on attitude towards mental illness in various other strata of people in our society and compare.

\section{REFERENCES}

[1] Beddington J, Cooper CL, Field J, et al. The mental wealth of nations. Nature 2008;455(7216):1057-60. [http://dx.doi.org/10.1038/4551057a].

[2] Sartorius N, Schulze H. Reducing the stigma of mental illness: a report from a Global Programme of the World Psychiatric Association. Geneva: World Health Organization, 2006.

[3] Kermode M, Bowen K, Arole S, et al. Community beliefs about causes and risks for mental disorders: a mental health literacy survey in a rural area of Maharashtra, India. Int J Soc Psychiatry 2010;56(6):606-22. [http://dx.doi.org/10.1177/0020764009345058].

[4] Raguram R, Weiss MG, Keval H, et al. Cultural dimensions of clinical depression in Bangalore, India. Anthropology Med 2001;8(1):31-46.

[5] Math SB, Chandrashekar CR, Bhugra D. Psychiatric epidemiology in India. Ind J Med Res 2007;126(3):183-92.

[6] Hannigan B. Mental healthcare in the community: an analysis of contemporary public attitudes towards, and public representations of, mental illness. J Ment Health 1999;8(5):431-40. 
[7] World Health Organization. Atlas: nurses in mental health. Geneva: WHO, 2007. www.who.int/ mental_health/evidence/nursing_atlas_2007.pdf

[8] Link BG, Struening EL, Rahav M, et al. On stigma and its consequences: evidence from a longitudinal study of men with dual diagnoses of mental illness and substance abuse. J Health Soc Behav 1997;38(2):11790.

[9] Kumar A, Goyal U, Ganesh KS, et al. Attitude of postgraduate residents towards psychiatry. Indian J Psychiatry 2001;43:97-101.

[10] Bhaskaran K. Undergraduate training in psychiatry and behavioral sciences. The need to train the trainees. Indian J Psychiatry 1990;32(1):1-3.

[11] Trivedi JK. Importance of undergraduate psychiatric training. Indian J Psychiatry 1998;40 (2):101-2.

[12] Nordt C, Rossler W, Lauber C. Attitudes of mental health professionals toward people with schizophrenia and major depression. Schizophrenia Bulletin 2006;32(4):709-14.

[13] The NHS Information Centre, Mental Health and Community: attitude to mental illness-2011 survey report.

[14] Arvaniti A, Samakouri M, Kalamara E, et al. Health service staff's attitudes towards patients with mental illness. Social Psychiatry and Psychiatric Epidemiology 2009;44(8):658-65.
[15] Hugo M. Mental health professionals' attitudes towards people who have experienced a mental health disorder. Journal of Psychiatric and Mental Health Nursing 2001;8(5):419-25.

[16] Brinn F. Patients with mental illness: general nurses' attitudes and expectations. Nursing Standard 2000;14(27):32-6.

[17] Poreddi V, Thimmaiah R, Pashupu DR, et al. Undergraduate Nursing Students' attitudes towards mental illness: implications for specific academic education. Indian J Psychol Med 2014;36(4):368-72.

[18] Aruna G, Mittal S, Yadiyal MB, et al. Perception, knowledge and attitude toward mental disorders and psychiatry among medical undergraduates in Karnataka: a cross sectional study. IJP 2016;58(1):706.

[19] Sireesha SR, Lanka UVR, Reddy JM, et al. A crosssectional and comparative study of stigma in undergraduate medical students towards mentally ill patients. Journal of Evolution of Medical and Dental Sciences 2015;4(94):15963-9. 